\title{
Madras pattern of motor neuron disease in South India
}

\author{
M GOURIE-DEVI，T G SURESH
}

From the Department of Neurology, National Institute of Mental Health and Neurosciences, Bangalore, India

SUMMARY This paper presents the clinical features in 12 patients with the Madras pattern of motor neuron disease (MMND) seen over a period of 10 years. Ten of the patients were from other parts of South India, outside Madras. Young age at onset, sporadic occurrence, sensorineural deafness, bulbar palsy, diffuse atrophy with weakness of limbs and progressive but benign course were the striking features. Electromyography revealed chronic partial denervation. MMND formed 3.7\% of all forms of motor neuron disease. Although isolated cases have been seen elsewhere in India, this is the first report of a large number of patients of MMND seen outside Madras (Tamil Nadu). Recognition of this clinical syndrome is of importance for prognostication and as well for search of possible aetiological factors.

A sub group of motor neuron disease in the younger age group was described from Madras, India by Meenakshisundaram et al in 1970. ${ }^{1}$ Subsequently this condition has been termed the Madras Pattern of Motor Neuron Disease (MMND) and the characteristic clinical features have been well recognised and documented. ${ }^{23}$ An essentially progressive but benign course, younger age at onset, absence of family history, persistent asymmetrical limb involvement, involvement of lower cranial nerves in two thirds of patients and sensorineural hearing impairment in a third of patients, are the striking features. From the same state of Tamil Nadu, (Madras being the capital city), another report has appeared from Vellore. ${ }^{4}$ Apart from the reports from Tamil Nadu, neurologists in other States of India have not seen similar patients except three patients in Bombay. ${ }^{56}$ During a symposium on motor neuron disease held at Bangalore, Karnataka, in India in 1984, this subject aroused considerable interest and it was clear from the discussions that only a few patients of MMND have been observed by neurologists outside Tamil Nadu. ${ }^{67}$ This paper reports the clinical features of 12 patients of MMND, 10 of them being from outside Tamil Nadu.

Address for reprint requests: Dr $M$ Gourie-Devi, Professor of Neurology, Department of Neurology, National Institute of Mental Health \& Neurosciences, Bangalore-560 029, India.

Received 3 November 1987.

Accepted 15 December 1987

\section{Methods}

The National Institute of Mental Health \& Neurosciences, Bangalore, South India, is a major centre in India and receives patients not only from the State of Karnataka where it is situated but also from other states in the country. During a 10 year period (1973 to 1982) 323 chronic anterior horn cell diseases were seen, of whom 12 patients belonged to the category of MMND.

A special protocol was designed for recording of place of residence, occupation, family history, antecedent events, age at onset, duration of illness, symptoms at initial presentation, findings on neurological examination, audiological testing, electroneuromyography, radiology and finally the degree and progression of the physical disability. Relevant investigations were done to exclude other disorders likely to cause a similar clinical picture.

\section{Results}

MMND patients formed $3 \cdot 7 \%$ (12) of the total group of chronic anterior horn cell disorders (323) which included amyotrophic lateral sclerosis, progressive muscular atrophy, spinal muscular atrophy, postpoliomyelitis progressive muscular atrophy and atypical forms comprising MMND and monomelic amyotrophy. ${ }^{7}$ All the 12 patients with MMND were from southern States of India (fig 1); nine were from Karnataka, one from Kerala and two from Tamil $\mathrm{Nadu}$; thus 10 of 12 patients were from outside Tamil $\mathrm{Nadu}$. These 10 patients were from places 250 to 600 $\mathrm{km}$ away from Madras. According to the records they had never visited or lived in Tamil Nadu. All were 


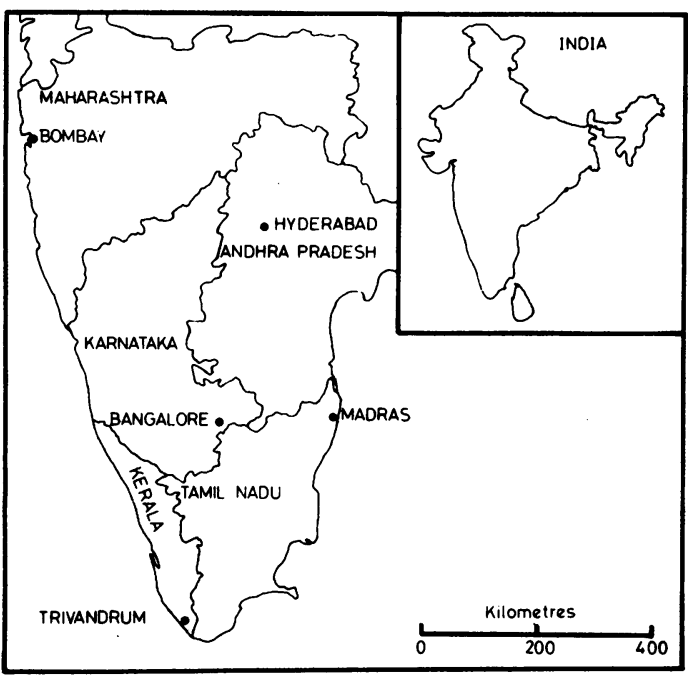

Fig 1 Map showing states in South India and part of West India (Inset-map of India).

sporadic in occurrence and there was no family history of similar or any other neurological disorder. The mean age at onset was 15.4 years with a range of 7 to 29 years (table). It is noteworthy that the age at onset in seven patients was between 5 to 15 years and in $75 \%$ of patients it was below 20 years (fig 2). Equal numbers of males and females were affected. Two patients (patients 3 and 7) were engaged in manual work while all the others had sedentary jobs. One third of the patients belonged to the middle income group and the rest to the low income group.

There were no significant antecedent events in nine patients. In one patient (patient 3) neurological symp- toms were noted 4 days after an insect bite over the cheek; in the second patient (patient 1) febrile illness of 10 days duration preceded the neurological symptoms and the third patient (patient 12) had jaundice, possibly infectious hepatitis, 3 months prior to the onset of neurological illness. Careful and detailed interrogation failed to reveal previous history of poliomyelitis, trauma, vaccination, electric shock or exposure to known toxic substances.

The onset was insidious in all patients and common initial symptoms were atrophy and weakness of limbs (10), defective hearing (10) and speech disturbances (8). Twitching of muscles (4), tremors of fingers (2), and dysphagia (2) were less commonly seen in the initial stages. Two patients (patient 5 and 7), had behaviour disturbances in the form of irritability, and a tendency to be abusive and violent; these changes appeared to be due to neglect by family members and further aggravated by reaction to disability particularly hearing loss. There was no documented evidence of intellectual deterioration.

\section{Cranial nerves}

There was clear evidence of bulbar motor cranial nerve involvement in 11 patients; hypoglossal nerve was the commonest (10 patients) to be affected, next in frequency were IX and $X$ cranial nerves (six patients). Bilateral facial nerve involvement was present in six patients while in three patients the motor trigeminal nerve was affected. None of the patients had any evidence of ptosis or disorder of eye movements.

\section{Sensorineural deafness}

The striking feature was the significant hearing loss (confirmed by audiometry) in 10 patients, while in one

Table Clinical features in 12 patients with Madras motor neuron disease

\begin{tabular}{|c|c|c|c|c|c|c|c|c|c|c|c|c|}
\hline & $l$ & 2 & 3 & 4 & 5 & 6 & 7 & 8 & 9 & 10 & 11 & 12 \\
\hline $\begin{array}{l}\text { Age at onset (yr) } \\
\text { Sex } \\
\text { Residence } \\
\text { Duration (yr) } \\
\text { Cranial nerve palsy }\end{array}$ & $\begin{array}{l}11 \\
\text { F } \\
\text { TN } \\
0 \cdot 5 \\
\text { VII, XII }\end{array}$ & $\begin{array}{l}22 \\
\text { M } \\
\text { TN } \\
1 \\
\text { V, VII, } \\
\text { XI }\end{array}$ & $\begin{array}{l}15 \\
\text { F } \\
\text { K } \\
2 \\
\text { V, VII, } \\
\text { IX, X, } \\
\text { XII }\end{array}$ & $\begin{array}{l}21 \\
\mathbf{M} \\
\mathbf{K} \\
1 \cdot 5 \\
-\end{array}$ & $\begin{array}{l}13 \\
\mathbf{M} \\
\mathbf{K} \\
10 \\
\text { IX, X, } \\
\text { XII }\end{array}$ & $\begin{array}{l}17 \\
\mathbf{M} \\
\mathbf{K} \\
\mathbf{3} \\
\mathbf{I X}, \mathbf{X} \\
\mathbf{X I I}\end{array}$ & $\begin{array}{l}7 \\
\mathbf{M} \\
\mathbf{K} \\
16 \\
\text { IX, X, } \\
\text { XII }\end{array}$ & $\begin{array}{l}10 \\
\mathbf{F} \\
\mathbf{K} \\
20 \\
\text { V, VII, } \\
\text { XII }\end{array}$ & $\begin{array}{l}11 \\
\text { F } \\
\text { K } \\
2 \\
\text { VII, IX, } \\
\text { X, XI, } \\
\text { XII }\end{array}$ & $\begin{array}{l}16 \\
F \\
K \\
0 \cdot 3 \\
\text { IX, X } \\
\text { XII }\end{array}$ & $\begin{array}{l}29 \\
\text { M } \\
\text { KE } \\
3 \\
\text { XII }\end{array}$ & $\begin{array}{l}12 \\
\mathbf{F} \\
\mathbf{K} \\
1 \\
\text { VII, }\end{array}$ \\
\hline Sensorineural deafness & + & - & + & + & + & + & + & + & + & + & + & + \\
\hline $\begin{array}{l}\text { Behavioural disturbances } \\
\text { Fasciculations }\end{array}$ & $\overline{+} \mathrm{T}$ & $\overline{+} \mathbf{L}$ & $\overline{+} \mathrm{T}$ & $\overline{+} \mathbf{L}$ & $\begin{array}{l}+ \\
+\mathrm{T}, \mathrm{L}\end{array}$ & & $\begin{array}{l}+ \\
+\mathrm{T}, \mathrm{L}\end{array}$ & $\overline{+} \mathrm{T}$ & $\overline{+} \mathrm{T}$ & $\overline{+} \mathrm{T}$ & $\overline{+} \mathbf{T}, \mathrm{L}$ & $\overline{+} \mathrm{T}$ \\
\hline $\begin{array}{l}\text { Minipolymyoclonus } \\
\text { Atrophy and weakness }\end{array}$ & + & + & - & + & - & - & - & - & - & - & + & - \\
\hline Limbs affected & ULs & ULs & ULs & ULs & $4 \mathrm{Ls}$ & $4 \mathrm{Ls}$ & ULs & - & - & ULs & ULs & ULs \\
\hline Distribution & Dist & $\begin{array}{l}\text { Dist } \\
\text { prox }\end{array}$ & Dist & $\begin{array}{l}\text { Dist } \\
\text { prox }\end{array}$ & $\begin{array}{l}\text { Dist } \\
\text { prox }\end{array}$ & $\begin{array}{l}\text { Dist } \\
\text { prox }\end{array}$ & Dist . & - & - & $\begin{array}{l}\text { Dist } \\
\text { prox }\end{array}$ & $\begin{array}{l}\text { Dist } \\
\text { prox }\end{array}$ & Dist \\
\hline $\begin{array}{l}\text { Symmetry or Asymmetry } \\
\text { Tendon reflexes }\end{array}$ & $\begin{array}{l}\text { Sym } \\
\text { UL-N } \\
\text { LL } \uparrow\end{array}$ & $\begin{array}{l}\text { Asym } \\
\text { 4LS† }\end{array}$ & $\begin{array}{l}\text { Sym } \\
\mathbf{N}\end{array}$ & $\begin{array}{l}\text { Sym } \\
\mathbf{N}\end{array}$ & $\begin{array}{l}\text { Sym } \\
\text { UL } \downarrow \\
\text { LL† }\end{array}$ & $\begin{array}{l}\text { Sym } \\
\text { 4LS } \downarrow\end{array}$ & $\begin{array}{l}\text { Sym } \\
\text { ULL } \downarrow \\
\text { LL† }\end{array}$ & $\overline{\mathbf{N}}$ & $\overline{\mathbf{N}}$ & $\begin{array}{l}\text { Sym } \\
\text { 4LS } \downarrow\end{array}$ & $\begin{array}{l}\text { Sym } \\
4 L S \uparrow\end{array}$ & $\begin{array}{l}\text { Sym } \\
\mathbf{N}\end{array}$ \\
\hline Abdominal reflexes & $\mathbf{N}$ & $\mathbf{N}$ & $\downarrow$ & $\mathbf{N}$ & $\mathbf{N}$ & $\mathbf{N}$ & $\mathbf{N}$ & $\downarrow$ & $\downarrow$ & $\mathbf{N}$ & $\mathbf{N}$ & $\mathbf{N}$ \\
\hline Babinski sign & + & + & - & - & + & + & + & + & + & + & + & - \\
\hline
\end{tabular}

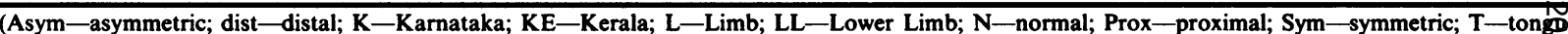
TN-Tamil Nadu; UL-upper limb). 


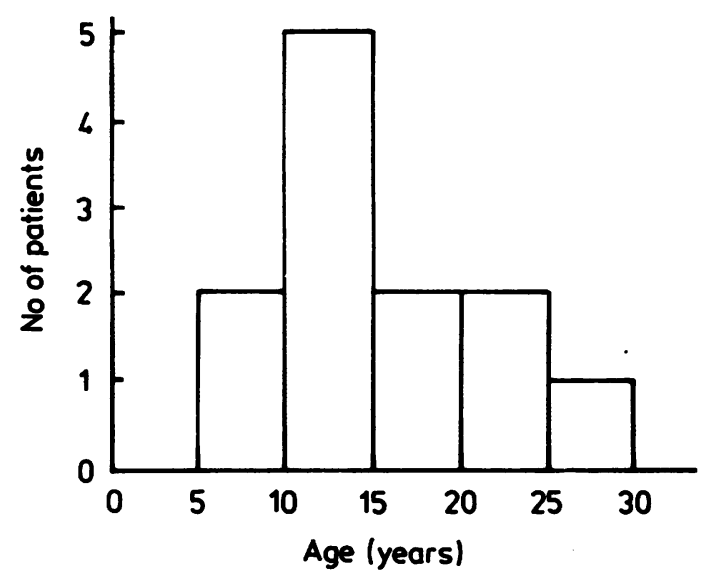

Fig 2 Age at onset in 12 patients of Madras Motor Neuron Disease.

patient (patient 3) although there was no symptom of defective hearing, audiometry revealed abnormality. The hearing loss was bilateral in 10 patients and unilateral in one patient. It is noteworthy that deafness preceded other neurological symptoms in three patients by $1 \frac{1}{2}, 10$ and 19 years; in four patients the symptom occurred simultaneously while in the remaining three patients neurological symptoms preceded the deafness by 1 to $1 \frac{1}{2}$ years. Insidious onset and slow progression of hearing loss was noted in half the patients. In the others the tempo of the illness was not clear. The disability due to hearing handicap was severe in five patients and mild to moderate in five patients.

\section{Motor system}

Motor weakness and atrophy were prominent features in 10 patients. Distal muscles of upper limbs were affected in all (fig 3), proximal muscles of upper limbs in 5 and distal muscles (leg and foot) of lower limbs in two patients. The atrophy was more marked than muscle weakness in all. In eight patients the weakness and atrophy were symmetric. The remaining two patients (patients 8,9 ) had isolated bulbar palsy without any evidence of atrophy or weakness of the limbs. One of them (patient 8) had mild spasticity of the lower limbs with normal tendon reflexes and gait disturbance. In five patients tendon reflexes were normal in all four limbs; brisk in two and sluggish in two patients. In the remaining three patients, they were brisk in the lower limbs but in the upper limbs in one patient they were normal and in two were sluggish. The superficial abdominal reflexes were normal in nine and sluggish in three patients. Extensor plantar response was seen in nine patients. Thus in nine patients there was convincing evidence of pyramidal signs.

\section{Other neurologic and systemic findings}

In one patient (patient 2) thickening of cutaneous nerves (greater auricular and saphenous nerves) unassociated with hypopigmented patches was detected. Further investigations excluded Hansen's disease. Another patient (patient 10) had asymptomatic mitral valve prolapse.

\section{Investigations}

Routine haemogram and blood tests were normal. Serum creatine kinase levels were mildly elevated in two patients. Cerebrospinal fluid examination, radiographs of cervical spine and craniovertebral junction and myelography did not reveal any abnormality. Concentric needle electromyography showed evidence of chronic denervation with reinnervation. Active denervation was evidenced by the presence of fibrillations and positive sharp waves in three patients.

\section{Discussion}

The classical motor neuron disease seen in India is similar to that in the west in the clinical picture and frequency of occurrence. However, the onset of the illness is about a decade earlier and the proportion of patients below the age of 30 is considerably high. ${ }^{7-13}$ Non-familial, progressive, often asymmetric amyotrophy of upper limbs, with onset in second or third decade, slow progression, and with pyramidal tract signs in lower limbs, rare occurrence of bulbar palsy and absence of perceptive deafness, has been frequently observed in India. ${ }^{14}$ In addition to these forms of motor neuron disease in the young, two specific types have been identified. Single limb involvement variously described as "juvenile muscular atrophy of upper extremity", 15-17 "monomelic amyotrophy", 18 "wasted leg syndrome"19 and "benign focal amyotrophy", ${ }^{20}$ has been recognised by neurologists in Japan and India where such patients seem to be more often seen than in the West. The second type, the Madras pattern of motor neuron disease was first described by Meenakshisundaram et al from South India in 1970. ${ }^{1}$ The authors reported 14 patients, and subsequently over the next 14 years further patients were observed and the recent report from the same centre documents 40 patients. $^{23}$ In the present series strict criteria for the diagnosis, placing emphasis on the occurrence of sensorineural deafness as the essential feature, have been used. Therefore it is possible that we could have overlooked some of the cases without eighth nerve involvement, which would otherwise satisfy the rest of the clinical profile. While deafness was noted in one third of the patients 

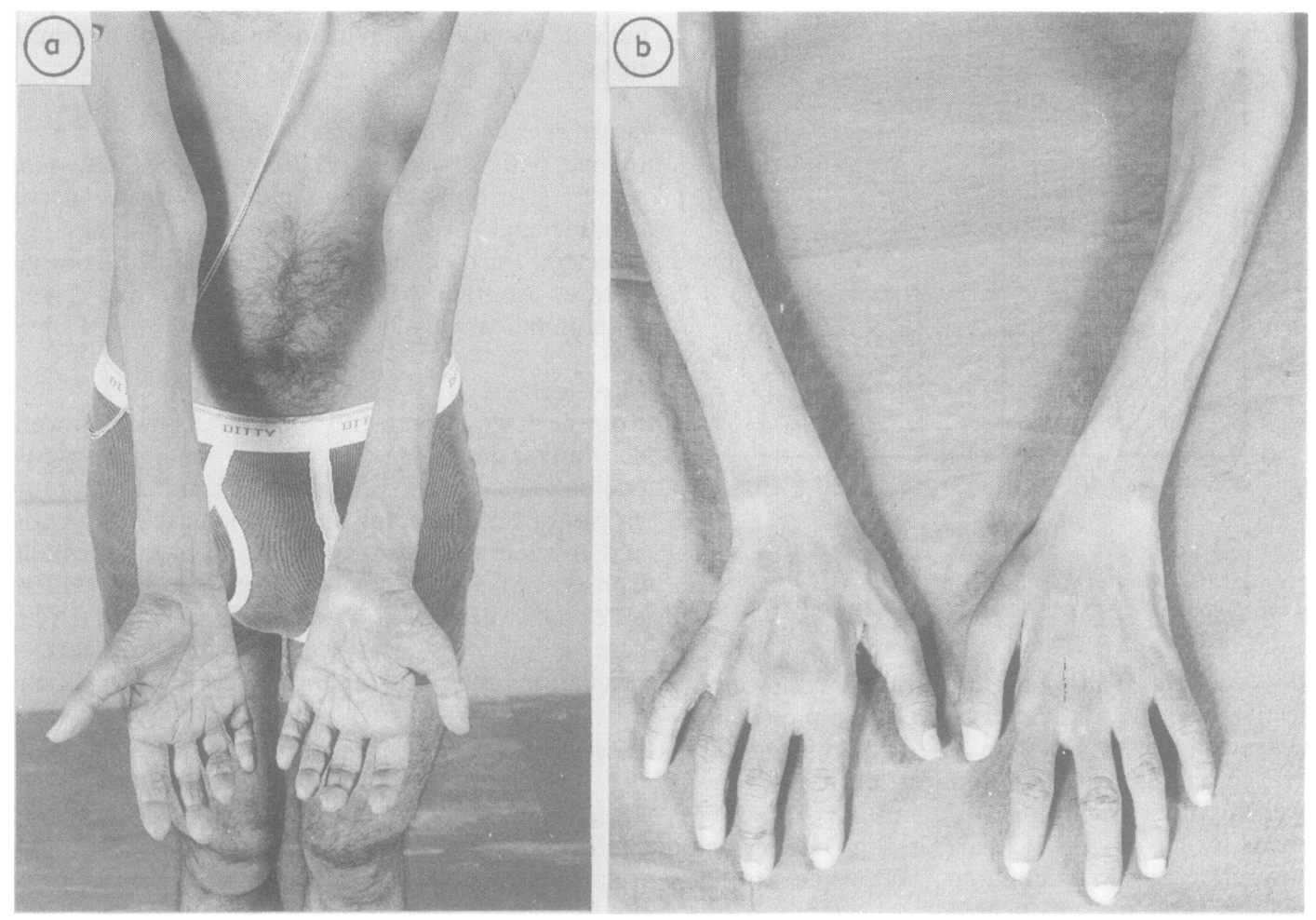

Fig 3a \& b Severe, symmetric atrophy of forearm and hand muscles in Madras Motor Neurone Disense (patient 4).

reported from Madras, ${ }^{1-3}$ it was seen in all but one $(92 \%)$ in our (Bangalore) series. Involvement of lower cranial nerve nuclei was also high $(92 \%)$ in our series compared with the Madras series $(70 \%)$. Persistent asymmetry in the distribution of weakness was noted to be in more than half of their patients, whereas it was less constant $(20 \%)$ in our experience. However, pyramidal tracts involvement was similar in the Madras (65\%) and Bangalore $(75 \%)$ series and impairment of higher intellectual functions, cerebellar and sensory signs were conspicuous by their absence. There was no positive family history, all being sporadic in occurrence as in the other reported patients. Equal numbers of males and females were found to be affected in our series, while in the Madras series, ${ }^{3}$ the ratio was 4:1. Another interesting feature which has not been commented on by others, but noted in one third of our patients was minipolymyoclonus in fingers. This is a fairly common feature in spinal muscular atrophies ${ }^{21}$ and monomelic amyotrophy. ${ }^{18} \mathrm{~A}$ characteristic biochemical finding of persistently low citrate and elevated pyruvate level has been described in patients with MMND. ${ }^{22}$

Electromyographic evidence of widespread chronic partial denervation with normal conduction studies points to anterior horn cells as the site of degeneration. Recent findings of absence of all BAER components bilaterally with electrocochleography showing bilateral preservation of cochlear microphonics suggests loss of acoustic nerve fibres and/or sensory cells in the spiral ganglion as the basis for the deafness. ${ }^{6}$ However, so far there is no necropsy verification. The course was one of slow progression in all. None were disabled to an extent of being bedridden or wheel chair bound. Even though bulbar palsy was common, in none was it severe enough to cause problems in swallowing even after years of progression. On the contrary, deafness was a severe handicap in five patients.

MMND resembles bulbo-pontine paralysis with neural deafness ${ }^{23}$ in clinical picture as well as the benign course of the disease. However, in the latter there is an autosomal recessive mode of transmission and one case had ataxic gait possibly due to spinocerebellar tracts involvement as was confirmed at necropsy. ${ }^{24}$ Furthermore, this patient also had retinitis pigmentosa. In the absence of necropsy reports it is difficult to draw any further conclusions. MMND can be easily distinguished from Fazio-Londe's disease, ${ }^{25}$ as the latter is characterised by autosomal recessive 
transmission, early age of onset, rarity of pyramidal signs, normal hearing and rapidly progressive fatal course. Sporadic juvenile amyotrophic lateral sclerosis, a rare disorder in the young, can be easily distinguished from MMND in view of the association of other neurological signs such as choreic movements, cerebellar ataxia, nystagmus and mental retardation and the absence of deafness and late involvement of bulbar nuclei. ${ }^{26}$

This study indicates that MMND is seen in other parts of India, though less commonly than in Madras. MMND constituted $10 \%$ of all motor neuron diseases in Madras and 3.7\% in our centre, less than the other variant, monomelic amyotrophy (8.3\%). Ten of our patients who were from other states of South India excluding Tamil Nadu, were from places 250 to 600 $\mathrm{km}$ remote from Madras. It may be mentioned that the sociocultural customs, dietary pattern and climatic condition do not significantly vary in different regions of South India.

There are no clues to the cause of this disease. Necropsy verification, virological studies and epidemiological surveys may throw light, especially when the common occurrence in South India is recognised.

\section{References}

1 Meenakshisundaram E, Jagannathan K, Ramamurthy B. Clinical pattern of motor neurone disease seen in younger age groups in Madras. Neurology (India) 1970;18(suppl 1):109-12.

2 Jagannathan $\mathrm{K}$. Juvenile motor neurone disease. In: Spillane JD, ed. Tropical Neurology. London: Oxford University Press, 1973:127-30.

3 Jagannathan K, Kumaresen G. Madras pattern of motor neurone disease. In: Gourie-Devi M, ed. Motor Neurone Disease. New Delhi: Oxford and IBH, 1987:191-3.

4 Mathai KV, Prabhakar S, Gnanamuthu C. Motor neurone disease in India. In: Chen KM, Yase Y, eds. Amyotrophic Lateral Sclerosis in Asia and Oceania, Taipei: Shyan-Fu Chou: National Taiwan University, 1984:91-100.

5 Wadia NH. State of art of motor neurone disease in India. In: Gourie-Devi M, ed. Motor Neurone Disease. New Delhi: Oxford and IBH, 1987: 237-41.

6 Wadia PN, Bhatt MH, Misra VP. Clinical neurophysiological examination of deafness associated with juvenile motor neurone disease. J Neurol Sci 1987;78:29-33.

7 Gourie-Devi M, Suresh TG, Shankar SK. Pattern of motor neurone disease in South India and Monomelic amyotrophy (a benign atypical form). In: Gourie-Devi M, ed. Motor Neurone Disease. New Delhi: Oxford and IBH, 1987: 171-90.

8 Bharucha EP, Bharucha NE, Bhandari SN. Motor neurone disease in West India. In: Gourie-Devi M, ed
Motor Neurone Disease. New Delhi: Oxford and IBH, 1987:165-70.

9 Chopra JS, Prabhakar S, Singh AP, Banerjee AK. Pattern of motor neurone disease in North India and wasted leg syndrome. In: Gourie-Devi M, ed. Motor Neurone Disease. New Delhi: Oxford and IBH, 1987:147-63.

10 Virmani V, Vijayan G. Pattern of motor neurone disease in the young in North India. $J$ Assoc Physicians India 1975;23:695-701.

11 Sahadevan MG. Motor neurone disease: A clinical study. J Assoc Physicians India 1969;17:255-60.

12 Rai B, Jolly SS. Motor neurone disease: A clinical study. J Indian Med Assoc 1971;57:315-8.

13 Wadia RS, Karandikar R, Pallod S, Grant KB, Sardesai HV. Diseases of the anterior horn cell. J Assoc Physicians India 1972;20:416-22.

14 Wadia NH. An introduction to neurology in India. In: Spillane JD, ed. Tropical Neurology. London: Oxford University Press, 1973;25-36.

15 Hirayama K, Toyokura Y, Tsubaki T. Juvenile muscular atrophy of unilateral upper extremity; A new clinical entity. Psychiatria et Neurologia Japonica 1959;61:2190-7.

16 Sobue I, Saito N, Iida M, Ando K. Juvenile type of distal and segmental muscular atrophy of upper extremities. Ann Neurol 1978;3:429-32.

17 Singh N, Sachdev KK, Susheela AK. Juvenile muscular atrophy localised to arms. Arch Neurol 1980;37:297-9.

18 Gourie-Devi M, Suresh TG, Shankar SK. Monomelic amyotrophy. Arch Neurol 1984;41:388-94.

19 Prabhakar S, Chopra JS, Banerjee AK, Rana PVS. Wasted leg syndrome: A clinical, electrophysiological and histopathological study. Clin Neurol Neurosurg 1981;83:19-28.

20 Adornato BT, Engel WK, Kucera J, Bertorini TE. Benign focal amyotrophy. Neurology 1978;28:399.

21 Spiro A. Minipolymyoclonus: A neglected sign in childhood spinal muscular atrophy. Neurology 1970;20:1124-6.

22 Valmikinathan K, Mascreen M, Meenakshisundaram E, Snehalatha C. Biochemical aspects of motor neurone disease-Madras pattern. $J$ Neurol Neurosurg Psychiatry 1973;36:753-6.

23 Konigsmark BW. Hereditary diseases of the nervous system with hearing loss. In: Vinken PJ, Bruyn GW, eds. Handbook of Clinical Neurology, vol 22. Amsterdam: North-Holland Publishing Co, 1975;499-526.

24 Alberca R, Montero C, Ibanez A, Segura DI, MirandaNieves G. Progessive bulbar paralysis associated with neural deafness. A nosological entity. Arch Neurol 1980;37:214-6.

25 Gomez MR, Clermont V, Bernstein J. Progressive bulbar paralysis in childhood (Fazio-Londe's disease). Report of a case with pathologic evidence of nuclear atrophy. Arch Neurol 1962;6:317-23.

26 Gomez MR. Motor neurone diseases in children. In: Engel AG, Banker BQ, eds. Myology, Basic and Clinical, vol 2, New York: McGraw-Hill Book Company, 1986;1993-2012. 